\title{
THE ADHESIVE MECHANISMS OF MONO- GENETIC TREMATODES: THE ATTACHMENT OF SPECIES OF THE DICLIDOPHORIDAE TO THE GILLS OF GADOID FISHES
}

\author{
By J. Llewellyn \\ Department of Zoology and Comparative Physiology, \\ University of Birmingham
}

\section{(Plate I and Text-figs. I-3)}

An account of the adhesive organs of Diclidophora denticulata and of the attachment of this parasite to the gills of Gadus virens was given by Cerfontaine $(\mathrm{I} 896, \mathrm{I} 898)$ in what has come to be regarded (Dawes, I947) as a classic piece of description. The adhesive organs of other species of Diclidophora have been described by Gallien (1937) and Brinkmann (1942), while Price (1943), Sproston (1945, I946), Dawes (1946, I947), Chauhan (1953), and Hargis (1955) have made extensive use of the structure of adhesive organs in systematic surveys of the Diclidophoroidea. However, a consideration of all these accounts, in order to compare the structure of the adhesive organs of the Diclidophoridae with those of Plectanocotyle gurnardi and Kuhnia scombri which I have described previously (Llewellyn, I956a, I957a), showed that some of the more recent accounts were in very considerable conflict with Cerfontaine's description of Diclidophora denticulata, but that no actual comparisons had been made. In the present paper a comparative study is made, from actual specimens, of what are probably all of the valid species reported so far as belonging to the genus Diclidophora.

Specimens were obtained from the sources indicated in Table I, and have been named as in Sproston (I946, pp. 469-85). In addition to the species of Diclidophora listed by Sproston, D. gadi (Reichenbach-Klinke, I95I), syn. Dactylocotyle gadi Reichenbach-Klinke, I95I, has been studied from wholemount preparations. It has not been possible for me to examine Diclidophora maccallumi (Price, 1943) Sproston, I946, but from Price's diagram (I943, fig. 5) of the adhesive organ, this species seems more likely to belong to the Cyclocotylinae than to the Diclidophorinae. With regard to Diclidophora morrhuae (van Beneden \& Hesse, I863) Sproston, I946, it seems probable that no such animal exists: Dawes (1947, p. 107) stated that the identity of the species was very doubtful; Gallien (I937) searched for, but did not find any monogenean on cod; and I have examined about fifty specimens of Gadus morrhua without finding a trematode gill parasite; a comparatively 
great amount of fisheries work has been done on cod, and it is unlikely that a gill trematode would have escaped attention.

The histological techniques used have been those described previously (Llewellyn, I956a, I957a).

TABLE 1. SOURCES OF DICLIDOPHORA MATERIAL

\begin{tabular}{|c|c|c|}
\hline Parasite & Host & Locality \\
\hline D. merlangi & Gadus merlangus & $\begin{array}{l}\text { Aberystwyth } \\
\text { Plymouth }\end{array}$ \\
\hline D. denticulata & G. virens & $\begin{array}{l}\text { Irish Atlantic Slope } \\
\text { St Andrews }\end{array}$ \\
\hline D. luscae & G. luscus & Plymouth \\
\hline D. macruri & Macruris rupestris & Skager-Rak \\
\hline D. minor & Gadus poutassou & Skager-Rak and Nor \\
\hline D. palmata & Molva molva & $\begin{array}{l}\text { Irish Atlantic Slope } \\
\text { Iceland }\left(64^{\circ} 20^{\prime} \mathrm{N} . \text {, }\right. \\
\left.14^{\circ} \mathrm{I} 9^{\prime} \text { W. }\right)\end{array}$ \\
\hline D. phycidis & Urophycis blennoides & Irish Atlantic Slope \\
\hline D. pollachii & Gadus pollachius & Plymouth \\
\hline D. gadi & G. aeglefinus & North Sea \\
\hline
\end{tabular}

Collector

Rees \& Llewellyn (I94I) Llewellyn $(1956 b)$

Rees \& Llewellyn (r94I)

Frankland (I955)

Llewellyn (1956 $b$ )

Brinkmann (1942)

Brinkmann (1942)

Rees \& Llewellyn (I94I)

King Edward's School

Five Ways Birmingham Marine Expedition, 1956

Rees \& Llewellyn (I94I)

Llewellyn (I956 b)

Reichenbach-Klinke

(I95I)

\section{THE ADHESIVE MECHANISM OF DICLIDOPHORA}

A comparative account of the adhesive attitudes of several species of Diclidophora has been given previously (Llewellyn, I956b), and is further illustrated here for D. denticulata in Pl. I, fig. I. In all species, each of the eight adhesive organs grasps secondary gill lamellae in exactly the same manner, and, moreover, the general structure of all of the adhesive organs in all species is very similar, and is illustrated in Text-figs. I and 2. There are minor specific differences, and these will be described later (pp. 72-73). As far as possible, Cerfontaine's notation for the identification of various structures has been adopted, but some modifications and extensions to his scheme have been found necessary.

\section{The structure of the adhesive organs}

Each adhesive organ consists of a pair of dissimilar opposable hinged jaws that grasps two or three secondary gill lamellae so that the anterior jaw lies distally with respect to the origin of the primary lamella from the gill arch of the host fish, and the posterior jaw proximally (Pl. I, fig. I). The anterior jaw is deeply hollowed and is relatively fixed, while the posterior jaw is shallow and is movable about its hinged attachment to the anterior jaw, the movement being effected by both intrinsic and extrinsic muscles. The walls of the adhesive organ are supported by sclerites (= skeletal bars, plates, nodules and teeth), the arrangement of which is asymmetrical, making it possible to 
recognize an 'inner' (more median) and an 'outer' (more lateral) half to each organ (Text-figs. I and 2).

The inner half of the anterior jaw is supported by two fused sclerites, one, $a\left(=a_{1} a_{2} a_{3} a_{4}\right)$, in the median region of the jaw, and the other, $c\left(=c_{1} c_{2} c_{3}\right)$, a peripheral bar. Bar $a$ is a curved rod passing $\left(a_{1}\right)$ from a median distal

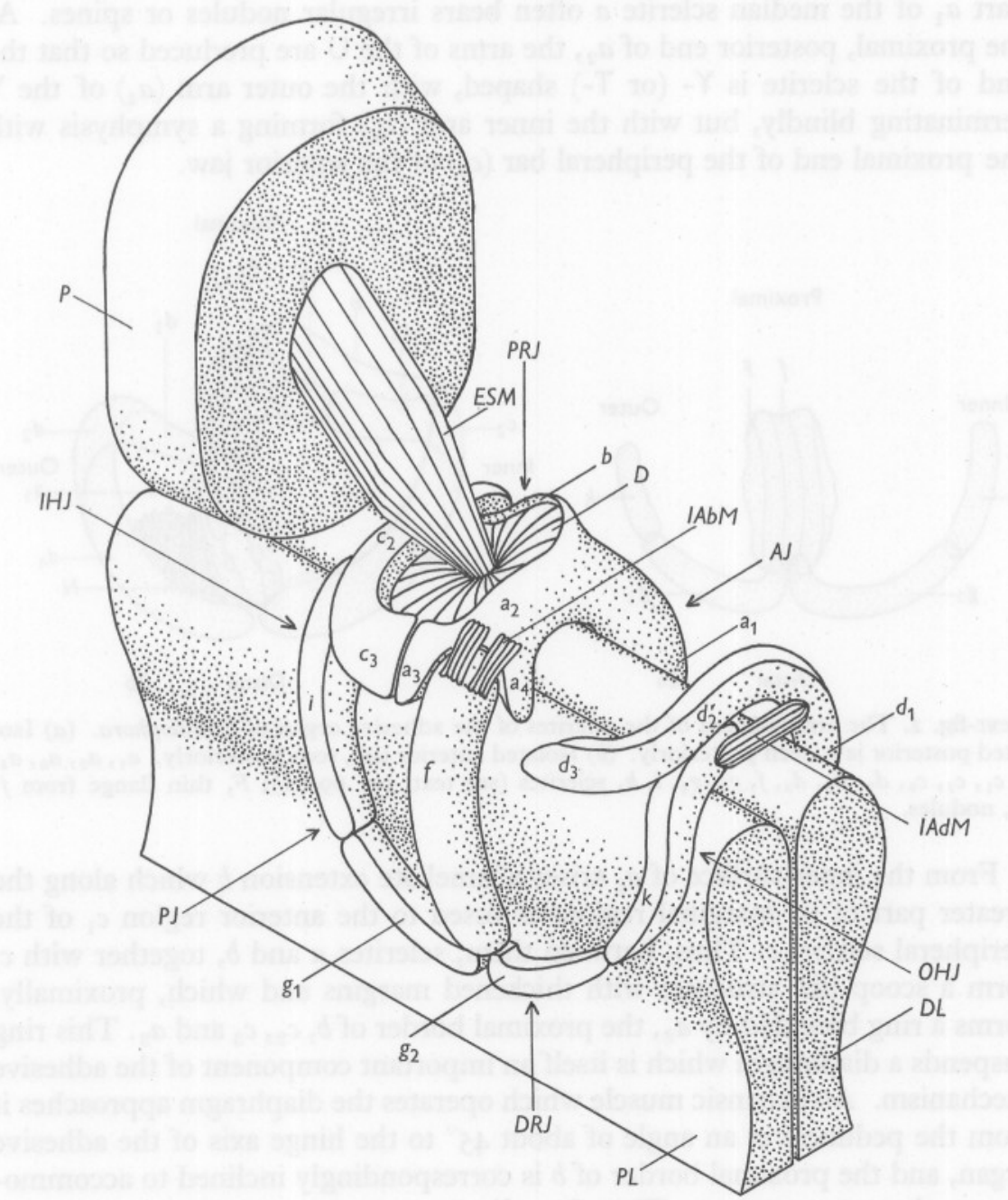

Text-fig. I. Stereogram of an adhesive organ of Diclidophora grasping secondary gill lamellae of host. $a_{1}, a_{2}, a_{3}, a_{4}, b, c_{2}, c_{3}, d_{1}, d_{2}, d_{3}, f, g_{1}, g_{2}, i, k$, sclerites (see text, pp. 69-7I); $A \mathcal{F}$, anterior jaw; $D$, diaphragm; $D L$, distal lamella; $D R \mathcal{F}$, distal region of jaw; $E S M$, extrinsic suctorial muscle; $I A b M$, intrinsic abductor muscle; IAdM, intrinsic adductor muscle; $I H \mathcal{F}$, inner half of jaw; $O H \mathcal{F}$, outer half of jaw; $P$, peduncle; $P \mathcal{F}$, posterior jaw; $P L$, proximal lamella; $P R \mathcal{A}$, proximal region of jaw. 
position in the anterior jaw to a median proximal position, where it curves posteriorly $\left(a_{2}\right)$ and articulates with the corresponding median bar $f$ of the posterior jaw. For most of its length sclerite $a$ is hollow, but, especially in its proximal region $a_{2}$, it may be $U$ - or $V$-shaped in section, with the opening of the $U$ directed away from the cavity of the adhesive organ, i.e. towards the peduncle bearing the adhesive organ. The anterior surface(s) of the anterior part $a_{1}$ of the median sclerite $a$ often bears irregular nodules or spines. At the proximal, posterior end of $a_{2}$, the arms of the $U$ are produced so that the end of the sclerite is $Y$ - (or T-) shaped, with the outer $\operatorname{arm}\left(a_{4}\right)$ of the $Y$ terminating blindly, but with the inner arm $\left(a_{3}\right)$ forming a symphysis with the proximal end of the peripheral bar $\left(c_{3}\right)$ of the anterior jaw.
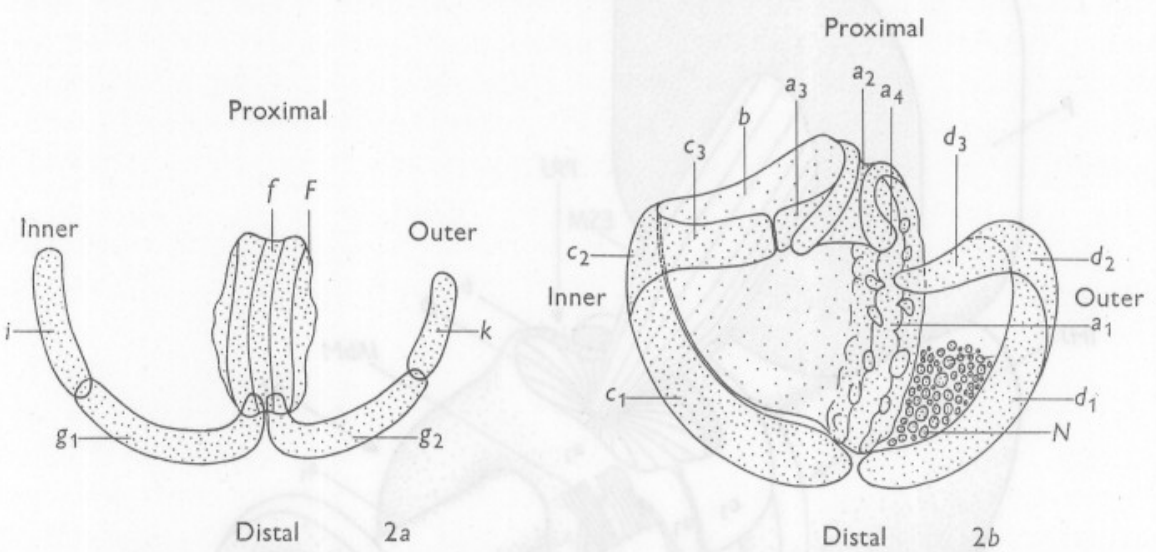

Text-fig. 2. The arrangement of the sclerites of the adhesive organ of Diclidophora. (a) Isolated posterior jaw, seen posteriorly. (b) Isolated anterior jaw, seen posteriorly. $a_{1}, a_{2}, a_{3}, a_{4}$, $b, c_{1}, c_{2}, c_{3}, d_{1}, d_{2}, d_{3}, f, g_{1}, g_{2}, i, k$, sclerites (see text, pp. 69-7I); $F$, thin flange from $f$; $N$, nodules.

From the inner surface of $a_{1}$ arises a lamellate extension $b$ which along the greater part of its marginal regions is fused to the anterior region $c_{1}$ of the peripheral sclerite $c$. Thus, between them, sclerites $a$ and $b$, together with $c$, form a scoop-like structure with thickened margins and which, proximally, forms a ring bounded by $a_{2}$, the proximal border of $b, c_{2}, c_{3}$ and $a_{3}$. This ring suspends a diaphragm which is itself an important component of the adhesive mechanism. An extrinsic muscle which operates the diaphragm approaches it from the peduncle at an angle of about $45^{\circ}$ to the hinge axis of the adhesive organ, and the proximal border of $b$ is correspondingly inclined to accommodate such an arrangement (Text-fig. $2 b$ ).

The outer half of the anterior jaw is supported by a single solid peripheral sclerite $d\left(=d_{1} d_{2} d_{3}\right)$ which curves in three different planes: first it borders the outer margin of the anterior jaw $\left(d_{1}\right)$, secondly it curves into the proximal region of the adhesive organ $\left(d_{2}\right)$, and thirdly it curves again, obliquely, into 
the plane of the posterior jaw $\left(d_{3}\right)$ and ends blindly at some distance distal to the outer spur $a_{4}$ from $a$, i.e. there is no fusion between $d$ and $a$.

On the anterior surface of the outer half of the anterior jaw (i.e. on the outside of the adhesive organ), in the region bounded by $a_{1}$ and $d_{1}$, there is present, in some species, a number of small sclerites, e.g. the 'teeth' of Diclidophora denticulata and the 'nodules' of D. luscae, but some species, e.g. D. palmata, are without corresponding structures.

The posterior jaw is supported by a median hollow rod $f$ hinged to sclerite $a$ of the anterior jaw, and by two pairs of solid peripheral sclerites, one pair $i$ and $k$ proximally with $i$ in the inner half of the jaw and $k$ in the outer, and one pair $g_{1}$ and $g_{2}$ distally with $g_{1}$ in the inner half of the jaw, and $g_{2}$ in the outer. The proximal ends of $i$ and $k$ are hinged on to the proximal arched portions $c_{2}$ and $d_{2}$ respectively of the peripheral sclerites of the anterior jaw, while the distal ends of sclerites $g_{1}$ and $g_{2}$ are immovably jointed to the distal end of the median sclerite $f$ of the posterior jaw. In most species $i$ and $g_{1}$ (and $k$ and $g_{2}$ ) are contiguous, but in D. denticulata $i$ is separated from $g_{1}$ (and $k$ from $g_{2}$ ) by a considerable gap.

The inner walls of the clamp are lined with slender rib-like sclerites similar to those illustrated previously for Plectanocotyle (Llewellyn, I956 a, Pl. I, figs. 5, 6, 8).

\section{The mode of action of the adhesive organs}

Each posterior adhesive organ of Diclidophora is operated by two distinct but co-ordinated mechanisms. First there is a set of intrinsic muscles consisting of three adductors connecting $i, f$, and $k$ of the posterior jaw with $c_{2}, a_{2}$ and $d_{2}$ respectively of the anterior jaw, and a median abductor, itself composed of two distinct muscle bundles, connecting $f$ with $a_{2}$ (Text-fig. I; P1. I, figs. 3, 6). By use of these antagonistic intrinsic muscles the jaws may be opened and closed, and in living specimens of $D$. merlangi, forcibly detached from the host tissue, I have seen the peduncle repeatedly extended with the jaws opening, and then the jaws rapidly snapped together and the peduncle withdrawn.

The second component of the adhesive mechanism consists of a suctorial device comprising the hinged jaws with their enclosed cavity bordered by soft lips, and a fibrous diaphragm suspended in the ring formed by the proximal regions of sclerites $a_{2} b c_{2} c_{3} a_{3}$, and actuated by the powerful extrinsic muscle. The extrinsic muscles of the adhesive organs are arranged in the same manner as I have illustrated previously for Plectanocotyle gurnardi (Llewellyn, I956a; Text-fig. 2). Other relatively small extrinsic muscles are associated with the adhesive organs, but these serve for orientating the organs, and play no part in the actual adhesive action.

The diaphragm consists of part of the fibrous wall of the adhesive organ, normally a structure consisting of fibres arranged perpendicularly between 
inner and outer basement membranes, in which the extrinsic muscle has perforated the outer or proximal (with respect to the peduncle) basement membrane to become inserted on to the central region of the inner basement membrane (Pl. I, fig. 3). At this region of insertion there may be sclerotization, the hardened tissue taking the form of irregular small nodules, or of a single disc, or of a ring or a pair of semicircular arcs. The degree of sclerotization of the central region of the diaphragm varies, not only among the different species of Diclidophora, but in different individuals and even between different adhesive organs of the same individual. Cerfontaine stated that there were such sclerotizations in all individuals of all the five species of Diclidophora that he had examined, and while this may well be so, it is perhaps worth while pointing out that sometimes it is only in sections that they may be identified.

The mode of action of the adhesive organs is the same in all species of Diclidophora. First the jaws are opened by the abductor muscle, then they are applied to two or three secondary gill lamellae, and a preliminary grasp is taken by the closing of the jaws by the intrinsic adductor muscles. Next follows the second and more important adhesive action: the powerful extrinsic muscle contracts, the central part of the diaphragm is withdrawn into the peduncle, the marginal lips of the jaws act as valves to seal off the internal cavity of the adhesive organ, and a suction pressure is set up in the cavity of the adhesive organ. The two jaws being freely hinged (the abductor muscle being relaxed), this pressure is converted into a clamping action which is proportional to the pull of the extrinsic muscle. The change in internal volume occasioned by the withdrawal of the diaphragm would be small, but the sea water in the clamp cavity would act as the agent for the very efficient hydraulic transmission of a suctorial action into a clamping action.

Variations in the structure of the adhesive organs in the different species of Diclidophora

Variations in the sizes and shapes of whole organs and of their component parts are illustrated in Text-fig. 3 .

D. merlangi (Text-fig. 3g). About 5-15 minute tubercles are present on the distal region of the outer surface of the outer half of the anterior jaw. The diaphragm sclerotization consists of a ring or of a pair of semicircular arcs.

D. denticulata (Text-fig. $3 a$ ). About 25-35 conical teeth are present on the outer surface of the outer half of the anterior jaw. The proximal and distal peripheral sclerites of the posterior jaw are separated from each other by a considerable gap. The diaphragm sclerotization is feeble or absent.

D. luscae (Text-fig. 3c). About 50-100 well-developed tubercles are present on the outer surface of the outer half of the anterior jaw. The diaphragm sclerotization is feeble or absent.

D. macruri (Text-fig. $3 f$ ). The width of the adhesive organ (=length of the hinge axis) is less than the length of the median sclerite $f$ of the posterior 
jaw, i.e. the clamp is narrower than its own length, whereas the clamps of all other species are wider than their own length. This difference is accompanied by a reduction of the posterior proximal region $d_{3}$ of the outer peripheral sclerite of the anterior jaw, and a corresponding increase in the length of $c_{3}$ in the inner half of the jaw, i.e. a greater proportion of the proximal surface of each clamp is involved in the suctorial mechanism.

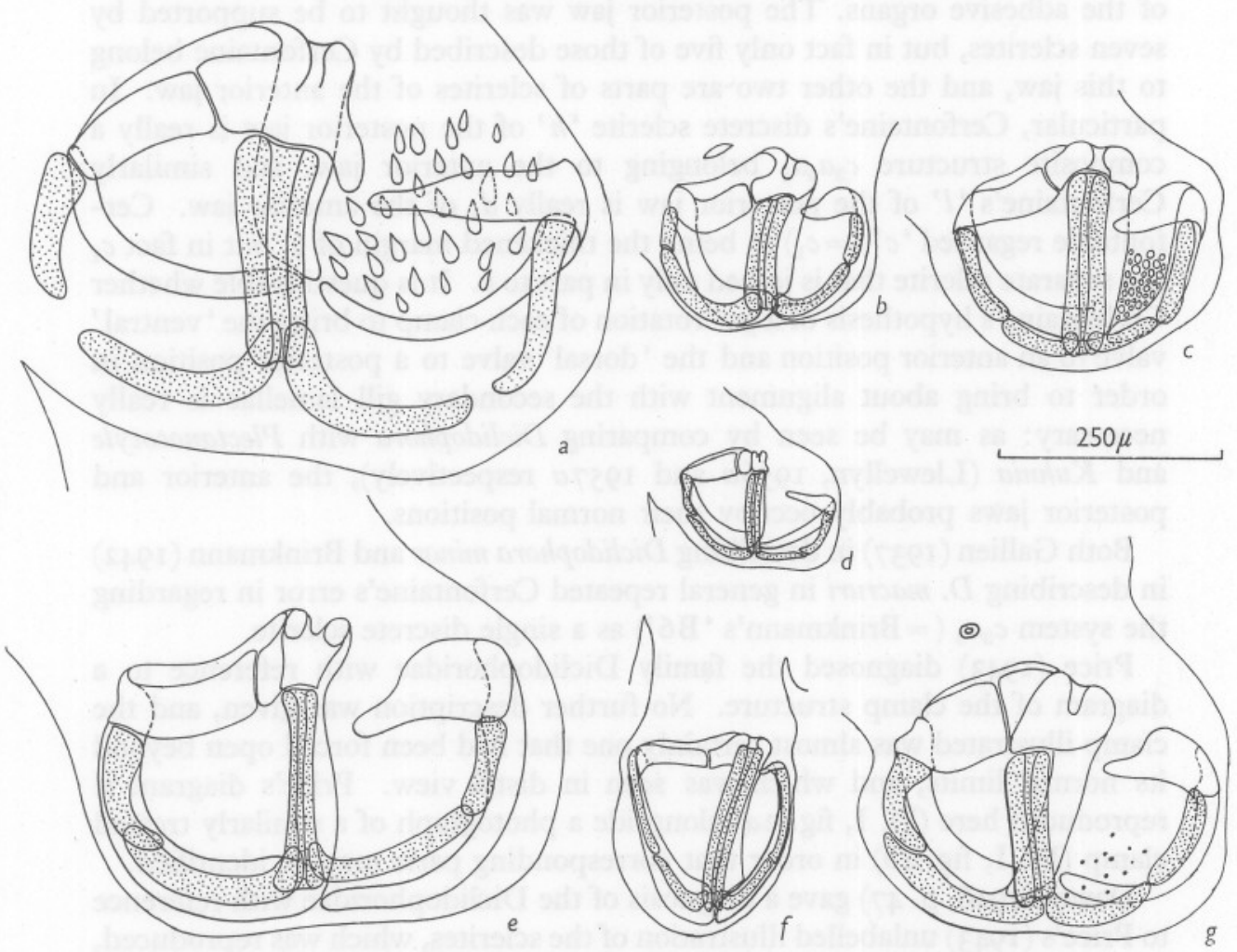

Text-fig. 3. Variations in size and shape of the sclerites of the adhesive organs of various species of Diclidophora, all drawn to the same scale. (a) D. denticulata, (b) D. phycidis, (c) D. luscae and D. pollachii, $(d) D$. minor, $(e) D$. palmata, $(f) D$. macruri, $(g) D$. merlangi and D. gadi.

D. minor (Text-fig. $3 d$ ). The sclerotization of the diaphragm is feeble or absent. No special features are present.

D. palmata (Text-fig. $3 e$ ). The sclerotization of the diaphragm is feeble or absent. No special features are present.

D. phycidis (Text-fig. $3 b$ ). The sclerotization of the diaphragm consists of a single well-developed disc.

D. pollachii (Text-fig. $3 c$ ). The adhesive organ resembles exactly that of D. luscae. 
D. gadi (Text-fig. 3g). The adhesive organ resembles exactly that of D. merlangi.

\section{Comparison with previous accounts of the adhesive organs of Diclidophora}

Cerfontaine (I896, I898) gave a generally accurate account of the adhesive mechanism of Diclidophora, but was mistaken in some aspects of the structure of the adhesive organs. The posterior jaw was thought to be supported by seven sclerites, but in fact only five of those described by Cerfontaine belong to this jaw, and the other two are parts of sclerites of the anterior jaw. In particular, Cerfontaine's discrete sclerite ' $h$ ' of the posterior jaw is really a composite structure $c_{3} a_{3} a_{4}$ belonging to the anterior jaw, and similarly Cerfontaine's ' $l$ ' of the posterior jaw is really $d_{3}$ of the anterior jaw. Cerfontaine regarded ' $c$ ' $\left(=c_{1}\right)$ as being the thickened margin of $b$, but in fact $c_{1}$ is a separate sclerite that is joined only in part to $b$. It is questionable whether Cerfontaine's hypothesis of a $90^{\circ}$ rotation of each clamp to bring the 'ventral' valve to an anterior position and the 'dorsal' valve to a posterior position in order to bring about alignment with the secondary gill lamellae is really necessary: as may be seen by comparing Diclidophora with Plectanocotyle and Kuhnia (Llewellyn, I956a and 1957 $a$ respectively), the anterior and posterior jaws probably occupy their normal positions.

Both Gallien (1937) in describing Diclidophora minor and Brinkmann (1942) in describing $D$. macruri in general repeated Cerfontaine's error in regarding the system $c_{3} a_{3}$ (=Brinkmann's 'B6') as a single discrete sclerite.

Price (1943) diagnosed the family Diclidophoridae with reference to a diagram of the clamp structure. No further description was given, and the clamp illustrated was almost certainly one that had been forced open beyond its normal limits, and which was seen in distal view. Price's diagram is reproduced here (Pl. I, fig. $2 a$ ) alongside a photograph of a similarly treated clamp (Pl. I, fig. $2 b$ ) in order that corresponding parts may be identified.

Dawes (1946, p. 47) gave a diagnosis of the Diclidophoridae with reference to Price's (1943) unlabelled illustration of the sclerites, which was reproduced, and qualified the diagram with a description of the arrangement of the sclerites. Later, Dawes (1947) repeated this description, and gave a translation of Cerfontaine's account of the adhesive organs of $D$. denticulata accompanied by a reproduction of Cerfontaine's diagrams, and also included original diagrams, but without descriptions, of the adhesive organs of D. merlangi, D. palmata and D. denticulata. According to Dawes's description of Price's diagram, there are eight sclerites in all:

(i) 'Four pieces bordering the opening of the sucker ventrally.'

According to my interpretation, Price's diagram shows two or at most three such sclerites, and in fact there are two $\left(c_{1}\right.$ and $\left.d_{1}\right)$.

(ii) 'Two others bent at right angles, one part of each bordering the opening dorsally, the other being directed towards its centre.' 
These I take to be $g_{1}$ and $g_{2}$ bordering the opening, with $f$ directed towards the centre; such interpretation would impute a double structure to $f$ when it is in fact a single hollow bar (as was illustrated in Dawes, 1947, fig. I8c, in a reproduction of Cerfontaine's figure) that appears double as seen in optical section as shown in Pl. I, fig. $2 b$, and would make no provision for $i$ and $k$, which are shown clearly in Price's diagram.

(iii) 'Two others reinforcing the dorsal wall, one T-shaped, the other continuing the stem of the T above its limbs (thus $\dagger$ ).'

In the 1947 publication (p. 94) the description of these last two sclerites (i.e. (iii) above) was altered somewhat, but still referred to them as occurring in the dorsal wall and forming a cruciform arrangement, with the stem of the T-piece having a lamellar extension and with its fellow supporting the concavity of the organ.

It seems to me that Dawes's 'T-shaped piece with lamellar extension' can only be the bar extending from the centre of Price's diagram directly to the bottom and then curving to the left of the figure, and equivalent to $a_{1} a_{2}$. However, both in Price's illustration and in fact sclerite $a_{1} a_{2}$ is in the 'ventral' (=anterior) valve. This interpretation presents a further difficulty in that the continuation of the stem above the limbs of the T would be equivalent to $f$, which, in my interpretation of Dawes's description, is already occupied by the right-angled centrally directed bends from $g_{1}$ and $g_{2}$.

It may be concluded then that there are some rather fundamental inconsistencies in Dawes's descriptions of the adhesive organs of Diclidophora.

In two accounts, that in certain respects were conflicting, Sproston (1945, p. 193; 1946, pp. 471 and 472) described the structure of the clamps of the Diclidophoridae and of the Diclidophorinae (which contains the single genus Diclidophora) in terms of what were thought to be the homologies of the various sclerites throughout the superfamily Diclidophoroidea. According to this scheme, the most generalized pattern of sclerites survived in the Mazocraeidae, and the diclidophorid pattern was relatively advanced. It has been shown elsewhere (Llewellyn, 1957a) that Sproston's interpretation of the clamp of the Mazocraeidae was inaccurate, and the present study shows that the descriptions of the clamp of Diclidophora are also erroneous. Among the chief mistakes are the following:

(i) The lateral walls of the single hollow median sclerite $f$ of the posterior jaw were seen in optical section as two separate parallel bars that were then assumed to be derived from elongations of the 'middle loop' (= peripheral sclerites $g_{1}$ and $g_{2}$ ) so that the 'cuticularized tendon' or 'spring' (=median sclerites $f$ and $a_{1} a_{2}$ in my description) were correspondingly reduced and were represented by an irregular ring in the middle of the 'anterior' (= proximal) edge of the capsule. In fact, $f$ and $a_{1} a_{2}$ are the largest components of the sclerite system of Diclidophora, and far from being a 'spring', are articulated with each other in a hinge joint provided with adductor and abductor muscles 
as had been described by Cerfontaine, and as are illustrated here in Pl. I, figs. $2 b, 6$.

(ii) No reference was made to the lamellate extension $b$ from sclerite $a$.

(iii) More than half the main muscles were thought to be attached directly on to the inner moiety of the 'dorsal loop' $\left(=c_{3} a_{3}\right)$. In fact the whole of the main muscle ( $=$ the extrinsic muscle) is attached to the centre of the diaphragm, which is itself in part suspended by $c_{3} a_{3}$.

Sproston thought the adhesive organs of the Diclidophoroidea (excepting the Choricotylinae and Hexostomatidae) functioned as clamps (pincers) in which certain curved portions of the clamp skeleton were under strain when the main retractor muscles contracted, and straightened out and opened the mouth of the clamp when these muscles relaxed. (A similar arrangement had been described by Goto (I895, p. I48) in a general account of the adhesive organs of various polyopisthocotylineans, but in this case to explain a suctorial and not a clamping action). The main muscle bundle in the Diclidophoridae was described by Sproston as being attached to the "inner remnant of the dorsal loop', and though an incipient sucker was thought to be present in the Diclidophorinae, the whole organ was thought to maintain the usual function of a clamp. Since the 'spring' (=af) was thought to be reduced, and the 'sucker' to be only incipient, and since no explanation was offered as to how a muscle attached to the 'inner remnant of the dorsal loop' could operate the clamp, Sproston's accounts are without any feasible explanation of a clamping mechanism. In fact, the main muscle does not itself form an incipient sucker, but motivates a suctorial device which brings about a clamping action. Moreover, there is absolutely no evidence for a 'spring mechanism', since except for the limitations imposed by the muscular attachments, the posterior jaw of the clamp is freely hinged at its three regions of attachment to the anterior jaw.

Chauhan (1953), in a key to the families of the Diclidophoroidea, used Sproston's terms for diclidophoroidean sclerites, but accepted Price's characters in diagnosing the Diclidophoridae.

Hargis (1955), in the course of a review of the families of monogenean parasites from fishes of the Gulf of Mexico, stated that he agreed with Sproston's establishment of the homology of the clamp sclerites of the diclidophorid subfamilies Diclidophorinae and Choricotylinae with those of less modified clamps, and it is therefore unnecessary to repeat the comparisons already made above.

\section{DISCUSSION}

The present investigation of the adhesive organs of Diclidophora has confirmed Cerfontaine's conception of a hinged clamp operated by both intrinsic muscles and a suctorial device, and thus disagrees completely with Sproston's theory of a 'sprung' clamp operated by extrinsic muscles attached to the skeletal framework. 
The comparative survey has shown that there is a basic arrangement of sclerites that is common to all species of Diclidophora, and this common pattern is compared in Table 2 with the pattern of sclerites in two diclidophoroideans that I have studied previously, viz. Plectanocotyle gurnardi and Kuhnia scombri. It is considered that no useful purpose would be served by speculating further upon the homologies of the various sclerites until representatives of other polyopisthocotylinean families have been examined in detail.

TABLE 2. THE CORRESPONDENCE OF SCLERITES IN THREE DICLIDOPHOROIDEAN GENERA

\begin{tabular}{|c|c|c|c|}
\hline & $\begin{array}{l}\text { Diclidophora } \\
\text { (Present paper) }\end{array}$ & $\begin{array}{c}\text { Plectanocotyle } \\
\text { (Llewellyn, 1956a) }\end{array}$ & $\begin{array}{c}\text { Kuhnia } \\
\text { (Llewellyn, I957a) }\end{array}$ \\
\hline $\begin{array}{c}\text { Peripheral sclerites } \\
\text { Anterior jaw } \\
\text { Posterior jaw }\end{array}$ & $\begin{array}{l}c_{1} c_{2} c_{3}, d_{1} d_{2} d_{3} \\
i g_{1} g_{2} k\end{array}$ & $\begin{array}{l}b_{1} b_{2} b_{3} \\
c d c\end{array}$ & $x^{2}=0$ \\
\hline $\begin{array}{l}\text { Median sclerites } \\
\text { Anterior jaw } \\
\text { Posterior jaw }\end{array}$ & $\begin{array}{l}a_{1} a_{2} a_{3} a_{4} \\
f\end{array}$ & $a$ & $f c d(+b ?)$ \\
\hline
\end{tabular}

A comparison of the variations in the structure of the clamps in the different species of Diclidophora yields information that may be of taxonomic importance. The adhesive organ of $D$. pollachii is quite indistinguishable from that of $D$. luscae, and this observation has prompted an examination of the specific diagnoses of these two parasites. In a sample of sixteen specimens of $D$. luscae and of two specimens of D. pollachii, which I collected from hosts of which the identification was confirmed by an experienced student of fishes, I found the characters listed by Cerfontaine (1898) to be insufficient to separate the parasites, and my identification of the parasites rests solely upon host specificity. Under these circumstances it would be highly desirable (but very difficult) to carry out experiments on host specificity in D. pollachii and D. luscae.

The adhesive organ of $D$. gadi was found to resemble exactly that of D. merlangi, in size, shape, the presence of minute tubercles on the anterior jaw, and in the presence of a ring-shaped sclerotization of the diaphragm. In fact, excepting for Reichenbach-Klinke's (I95I) diagnostic feature concerning the hook shape of the anterior polar filament of the egg capsule (actually it is the posterior, or ab-opercular polar filament which was illustrated as being hook-shaped), the two specimens of D. gadi I have examined are quite indistinguishable from $D$. merlangi. In the course of studies on larval monogeneans (Llewellyn, I957b) I have observed that egg capsule formation may continue in moribund parasites, with the formation, often, of abnormally shaped capsules. It is possible, therefore, that 'Diclidophora gadi ReichenbachKlinke, I95I' is really D. merlangi from an unusual host, Gadus aeglefinus.

Finally, it is suggested that the development of tubercles or teeth on the anterior jaws of the adhesive organs is an indication of the closer affinity 
between the species of Diclidophora parasitizing the host'genus Gadus (Diclidophora minor on Gadus poutassou representing the survival of the ancestral condition without tubercles) than between these species and the diclidophoran parasites on the host genera Molva, Urophycis and Macruris.

It is a pleasure to acknowledge the great help given to me by the Director and Staff of the Plymouth Laboratory. I am also pleased to express my gratitude to Prof. A. Brinkmann of Bergen and to Prof. O. Nybelin of Gothenburg for the loan of whole-mount preparations and serial sections of Diclidophora minor and D. macruri, to Dr H. H. Reichenbach-Klinke of Brunswick for the loan of specimens of D. gadi, to Dr H. M. T. Frankland for the gift of specimens of D. denticulata from St Andrews, and to Mr J. E. Saunders and members of the Sixth Form at King Edward's School, Five Ways, Birmingham, for collecting fresh specimens of $D$. palmata from ling off the coast of Iceland.

\section{SUMMARY}

An investigation of the adhesive mechanisms in all nine species of the genus Diclidophora has shown that there is a common structure consisting of a pair of hinged jaws operated by intrinsic muscles and also by a more powerful extrinsic muscle which acts on a diaphragm to produce a suction pressure that is converted into a clamping action. This investigation has revealed errors in Cerfontaine's and other descriptions of the anatomy of Diclidophora adhesive organs, but substantiates Cerfontaine's account of the adhesive mechanism, and therefore disagrees completely with the more recent account given by Sproston.

\section{REFERENCES}

Brinkmann, A., I942. On some new and little known Dactylocotyle species, with a discussion on the relations between the genus Dactylocotyle and the 'Family' Diclidophoridae. Göteborgs VetenskSam. Handl., Följ. VI, Ser. B, Bd. I, No. I3, $32 \mathrm{pp}$.

Cerfontaine, P., I896. Contribution à l'étude des Octocotylidés. I-III. Arch. Biol., Paris, T. 14, pp. 497-560.

— I898. Contribution à l'étude des Octocotylidés. IV. Arch. Biol., Paris, T. 15, pp. $301-28$.

Chauhan, B. S., I953. Studies on the trematode fauna of India. Part I. Subclass Monogenea. Rec. Indian Mus., Vol. 51, pp. I13-208.

Dawes, B., 1946. The Trematoda. Cambridge University Press.

- 1947. The Trematoda of British Fishes. London: The Ray Society.

FrankLand, H. M. T., 1955. The life history and bionomics of Diclidophora denticulata (Trematoda: Monogenea). Parasitology, Vol. 45, pp. 313-5I.

GALLIEN, L., I937. Recherches sur quelques trématodes monogénèses nouveaux ou peu connus. Ann. Parasit. hum. comp., T. 15, pp. I46-54.

Goto, S., 1895. Studies on the ectoparasitic trematodes of Japan. F. Coll. Sci. Tokyo, Vol. 8, pp. I-273. 

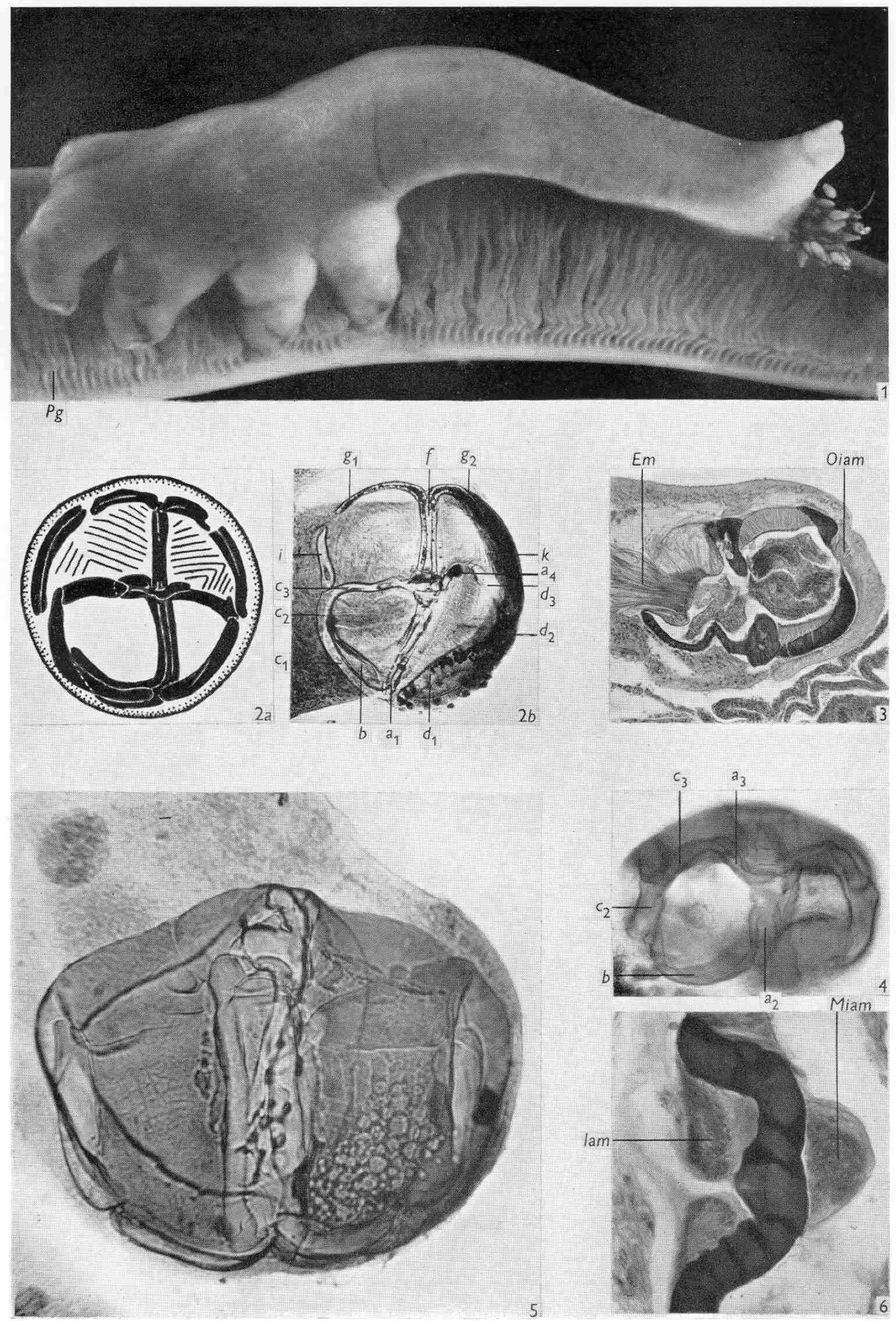

(Facing page 78) 
HARGIS, W. J., 1955. Monogenetic trematodes of Gulf of Mexico fishes. Part IX. The family Diclidophoridae Fuhrmann, 1928. Trans. Amer. micr. Soc., Vol. 74, pp. $377-88$.

Llewellyn, J., 1956 $a$. The adhesive mechanisms of monogenetic trematodes: the attachment of Plectanocotyle gurnardi (v. Ben. \& Hesse) to the gills of Trigla. F. mar. biol. Ass. U.K., Vol. 35, pp. 507-I4.

— $1956 \mathrm{~b}$. The host-specificity, micro-ecology, adhesive attitudes, and comparative morphology of some trematode gill parasites. F. mar. biol. Ass. U.K., Vol. 35, pp. II3-27.

1957a. The mechanism of the attachment of Kuhnia scombri (Kuhn, 1829)

(Trematoda: Monogenea) to the gills of its host Scomber scombrus L., including a note on the taxonomy of the parasite. Parasitology, Vol. 47, pp. 30-9.

- $1957 b$. The larvae of some monogenetic trematode parasites of Plymouth fishes. F. mar. biol. Ass. U.K., Vol. 36, pp. 243-59.

PRICE, E. W., I943. North American monogenetic trematodes: VI. The family Diclidophoridae (Diclidophoroidea). F. Wash. Acad. Sci., Vol. 33, pp. 44-54.

ReEs, G. \& Llewellyn, J., I94I. A record of the trematode and cestode parasites of fishes from the Porcupine Bank, Irish Atlantic Slope, and Irish Sea. Parasito$\log y$, Vol. 33, pp. 390-6.

REICHENBACH-KLINKE, H.-H., I95I. Eine neue art der trematodengattung Dactylocotyle am schellfisch (Gadus aeglefinus L.). Z. Parasit., Bd. I5, pp. 4-7.

Sproston, N. G., 1945. A note on the comparative anatomy of the clamps in the superfamily Diclidophoroidea (Trematoda: Monogenea). Parasitology, Vol. 36, pp. $191-4$.

- 1946. A synopsis of the monogenetic trematodes. Trans. zool. Soc. Lond., Vol. 25, pp. 185-600.

\section{EXPLANATION OF PLATE I}

The adhesive mechanism of Diclidophora

Fig. I. Diclidophora denticulata attached to gills of Gadus virens.

Fig. 2. Clamp structure in the Diclidophoridae: fig. $2 a$, after Price (1943); fig. $2 b$, clamp of $D$. denticulata forced open and seen distally for comparison with Price's diagram.

Fig. 3. Vertical section of adhesive organ of D. palmata parallel to the longitudinal axis of the extrinsic muscle, and obliquely through the remainder of the clamp.

Fig. 4. Adhesive organ of D. luscae in proximal view to show the ring which supports the diaphragm.

Fig. 5. Adhesive organ of $D$. luscae, from a flattened specimen in which sclerites of both anterior and posterior valves are seen in transparency. For interpretation see Text-figs. I-2. Fig. 6. Transverse section of sclerite $a_{2}$ showing the median intrinsic abductor and adductor muscles.

Abbreviations: $a_{1}, a_{2}, a_{3}, a_{4}, b, c_{1}, c_{2}, c_{3}, d_{1}, d_{2}, d_{3}, f, g_{1}, g_{2}, i, k$, sclerites (see text, pp. 69-7I); Em, extrinsic muscle; Iam, intrinsic abductor muscles; Miam, median intrinsic adductor muscle; Oiam, outer intrinsic adductor muscle; $\mathrm{Pg}$, proximal end of gill. 